Eastern Illinois University

The Keep

Faculty Research \& Creative Activity

Family and Consumer Sciences

January 2012

\title{
Comparison of Nutritive Value, Cost, Viscosity and Acceptability among Developed Oral Nutritional Supplements and Commercially-Prepared Supplements
}

Melanie Burns

Eastern Illinois University, mdburns@eiu.edu

Christa R. Huxel

Eastern Illinois University

Kathleen A. O'Rourke

Eastern Illinois University, kaorourke@eiu.edu

Linda D. Simpson

Eastern Illinois University, 1dsimpson@eiu.edu

Follow this and additional works at: http://thekeep.eiu.edu/fcs_fac

Part of the Nutrition Commons

\section{Recommended Citation}

Burns, Melanie; Huxel, Christa R.; O'Rourke, Kathleen A.; and Simpson, Linda D., "Comparison of Nutritive Value, Cost, Viscosity and Acceptability among Developed Oral Nutritional Supplements and Commercially-Prepared Supplements" (2012). Faculty Research \& Creative Activity. 22.

http://thekeep.eiu.edu/fcs_fac/22

This Article is brought to you for free and open access by the Family and Consumer Sciences at The Keep. It has been accepted for inclusion in Faculty Research \& Creative Activity by an authorized administrator of The Keep. For more information, please contact tabruns@eiu.edu. 


\section{Comparison of Nutritive Value, Cost, Viscosity and Acceptability among Developed Oral Nutritional Supplements and Commercially-Prepared Supplements}

Author(s): C. R. Huxel, M. T. Burns, K. A. O' Rourke, L. D. Simpson; Family and Consumer Sciences, Eastern Illinois Univ., Charleston, IL

Learning Outcome: The learner will be able to explain the quality characteristics of developed oral nutritional supplements for use by older adults.

Commercially available dietary supplements are high in cost, and consumer acceptability is limited. Oral nutritional supplements made in the home may help prevent, or delay, malnutrition in older adults. The objective of this study was to develop nutrient dense oral nutritional supplements in varying flavors which were lower in cost as compared to standard commercially-prepared supplements. Soymilk, soy powder, non-fat dry milk, and meal replacement shake mix were used to develop chocolate-, strawberry-, and vanilla-flavored supplements. The developed supplements and commercial supplements of varying flavors were evaluated for cost, nutritional composition, and viscosity. Using a Likert scale, eight dietitians rated appearance, aroma, flavor, aftertaste, and viscosity of each supplement. Multivariate analysis of variance determined if differences were significant in sensory data among the supplements. A post hoc Duncan's test determined differences in sensory attribute(s) and acceptability among the flavors. The developed supplements were lower in cost, significantly thicker (p_..001), yet nutritionally comparable to the commercial supplements. The developed supplements' aroma was significantly more appealing (p_.001), whereas the developed supplements' strength of flavor was perceived as significantly less strong compared to the commercial supplements (p_.026). Dietitians indicated preference to consume the developed chocolate and vanilla supplements. No significant differences were found among other sensory attributes or overall acceptability. The developed supplements were comparable to the standard commercially-prepared supplements. Future research should assess older adults' sensory evaluation and willingness to prepare supplements. Dietitians may use similar strategies to develop and recommend oral nutritional supplements for older adults. 